\title{
Prevalence and correlates of HIV infection among men who inject drugs in a remote area of Vietnam
}

Van T. Nghiem ${ }^{1,2^{*}}$, Thanh C. Bui ${ }^{3}$, Patrick P. Nadol ${ }^{4}$, Son H. Phan ${ }^{5}$, Binh T. Kieu', Ryan Kling ${ }^{7}$ and Theodore M. Hammett ${ }^{8}$

\begin{abstract}
Background: Lack of information on the HIV epidemic among men who inject drugs (MWID) in northwestern Vietnam, a remote area, may hamper national efforts to control the disease. We examined HIV prevalence, needle-syringe sharing behaviors, and associated factors among MWID in three areas of northwestern Vietnam.

Methods: We used descriptive analysis to report the characteristics, frequency of risk behaviors, and of access to healthcare services among the MWID. Univariable logistic regression was used to assess the associations between the HIV infection, needle-syringe sharing behaviors, and their independent variables. We further explored these associations in multivariable analyses where we included independent variables based on a priori knowledge and their associations with the dependent variables determined in univariable analyses $(p<0.25)$.

Results: The HIV prevalence was 37.9, 16.9, and 18.5\% for Tuan Giao, Bat Xat, and Lao Cai City, respectively, and 25.4\% overall. MWID of Thai minority ethnicity were more likely to be HIV-positive (adjusted odds ratio (AOR) 3.55; $95 \%$ confidence interval (CI) 1.84-6.87). The rate of needle-syringe sharing in the previous 6 months was approximately $9 \%$ among the MWID in Tuan Giao and Lao Cai City, and 27.8\% in Bat Xat. Two thirds of the participants never underwent HIV testing before this study. Ever having been tested for HIV before this study was not associated with any needle-syringe sharing behaviors. Among the HIV-positive MWID, those who received free clean needles and syringes were less likely to give used needles and syringes to peers (AOR 0.21 ; $95 \% \mathrm{Cl} 0.06-0.79$ ). Going to a "hotspot" in the previous week was associated with increased odds of needle-syringe sharing in multiple subgroups.

Conclusion: Our findings on HIV prevalence and testing participation among a subset of MWID in the northwestern Vietnam were corroborated with trend analysis results from the most recent HIV/STI Integrated Biological and Behavioral Surveillance report (data last collected in 2013.) We provided important insights into these MWID's risky injection behaviors. We suggest heightened emphasis on HIV testing and needle and syringe provision for this population. Also, policymakers and program implementers should target hotspots as a main venue to tackle HIV epidemics.
\end{abstract}

Keywords: Vietnam, HIV prevalence (or infection), Men who inject drugs, Risk behaviors

\footnotetext{
* Correspondence: vnghiem@fredhutch.org

${ }^{1}$ Department of Management, Policy and Community Health, University of

Texas Health Science Center at Houston School of Public Health, Houston, TX

77030, USA

${ }^{2}$ Southwest Oncology Group Statistical Center, Fred Hutchinson Cancer

Research Center, Seattle, WA 98109, USA

Full list of author information is available at the end of the article
} 


\section{Background}

In Vietnam, people who inject drugs comprised two thirds of the total human immunodeficiency virus (HIV) infections [1, 2]. Among that group, the vast majority (97\%) are male [3-5]. Previous studies have shown multiple risk factors for HIV infection among people who inject drugs. One factor is receiving or giving used needles and/or syringes from other users [6-8]. Also, visiting shooting galleries or drug injection "hotspots" or injecting in public areas is associated with an increased likelihood of sharing injection equipment and of HIV transmission [9, 10]. Other risk factors for HIV infection in this group include age, education level, monthly income, and socioeconomic status [11-13].

Interventions to prevent and control HIV/acquired immune deficiency syndrome (AIDS), such as needlesyringe programs, peer education and outreach, and voluntary HIV testing, have been implemented throughout the country. However, these interventions have been focused in large cities (e.g., Hanoi and Ho Chi Minh City) where Kinh, the country's majority ethnicity, populations are dense. Therefore, these interventions have primarily targeted the Kinh people. Minority people who inject drugs are disproportionately affected by poverty, lower education levels, and limited access to healthcare services, all of which put them at greater risk for HIV infection [14]. Des Jarlais and colleagues reported that minority people who inject drugs are twice more likely to be HIV positive than their majority ethnicity counterparts [15].

Ethnic minorities make up $14 \%$ of the Vietnamese population [16]. These minorities are concentrated in certain geographic areas that include the northwestern region. Men who inject drugs (MWID) in this region encounter challenges in accessing HIV/AIDS healthcare services, including limited communication materials in their dialects, low educational levels, limited HIV testing programs nearby, and difficulty in discreetly obtaining injection equipment [17]. The HIV/sexually transmitted infection (STI) Integrated Biological and Behavioral Survey (IBBS) report of 2011 (data collected in 2009) showed some descriptive statistics of HIV infection and the HIV-related risk behaviors among people living in the northwestern region who inject drugs [18]. This report, however, did not examine potential associations between drug users' characteristics and their risk behaviors or HIV outcomes. In sum, very little is known about the prevalence of HIV, the prevalence of HIV-related risk behaviors, and associated factors among MWID in Vietnam's northwestern area. This lack of understanding may hamper development of effective HIV interventions for ethnic minorities and thus could compromise the national effort for HIV/AIDS prevention and control.
Given these gaps in knowledge, our study aimed to (1) estimate HIV prevalence, (2) examine factors associated with HIV infection (e.g., demographic characteristics, drug injection behaviors, and visiting drug injection "hotspots"), and (3) investigate factors associated with needle-syringe sharing behaviors among a subset of MWID in the northwest.

\section{Methods}

\section{Study design, sampling, and recruitment}

We collected data from a cross-sectional survey from April to June 2011. Study sites included Tuan Giao district (Dien Bien province) and Bat Xat commune and Lao Cai City (Lao Cai province). These study sites were chosen because of high MWID prevalence, based on local reports and insight from our research team after multiple site visits. To recruit participants, we intended to apply a two-stage sampling process, known as time and location (i.e., "hotspot") sampling. In our study, the term "hotspot" is preferred because it is from a Vietnamese term (diểm nóng) that is commonly used by MWID and is better understood by local HIV/AIDS researchers and staff. This method selected hotspots (locations) at a time that most MWID would be present and then implemented a random selection of MWID for each hotspot. However, a widespread anti-drug campaign before and during the time of data collection led to detention and concealment of many MWID. Therefore, we recruited all eligible participants at targeted hotspots and then used a chain referral method for further recruitment (i.e., all recruited participants were asked to refer other potential participants to the study). We continued the recruitment process until we reached the desired sample size. Eligibility criteria were being male, being 18 years old or older, and having last injected drugs within 1 month before the data collection. We focused on the MWID because, according to the local reports, very few females injected drugs in the region.

\section{Procedure}

At the selected hotspots, we screened the eligibility of potential participants and, if eligible, invited them to the designated data collection sites at a scheduled time. Those who participated in the study could refer other eligible MWID. Referred participants were instructed to contact the research team (via telephone or in person) to schedule the interview and blood test. When participants arrived at the collection site, research team members again checked participants' eligibility by asking screening questions about their drug injection behavior or inspecting the injection track marks. In the presence of a team member witness, a researcher read the description of the study, explained procedure details, and obtained oral informed consent from the participant. 
The research team had translators to communicate with the participants who did not speak the Kinh language. The Institutional Review Board of Abt Associates and the Ethics Committee of Centers for Disease Control and Prevention in the USA, and Hanoi School of Public Health's Ethical Review Board in Vietnam approved the study's research protocol and questionnaires. All of these boards approved oral informed consent because of potential severe consequences for participants if there were a confidentiality breach associated with a written consent.

After informed consent was obtained, a trained researcher used a structured questionnaire to conduct a 30- to 45 -min, face-to-face interview in a private room with each participant. Responses were recorded on paper and were entered into a computer-based statistical program. After the interview, the participant was provided with pre-test counseling. Then, the participant's blood was drawn by a trained phlebotomist from a local health center for HIV testing. Each participant received 50,000 Vietnamese Dong ( 2.40 US dollars) in compensation for his time and transportation. We transported the blood samples to provincial HIV/AIDS center laboratories for testing, according to national guidelines. Determine ${ }^{\text {tm }}$ HIV-1/2 (AbbottLaboratories", Tokyo, Japan) was used for rapid testing; two enzyme immunoassay tests including Genscreen $^{\text {Tx }}$ HIV-1/2 version 2 (Bio-Rad Laboratories, CA, USA) and Murex HIV 1.2.0 (Murex Biotech, Dartford, UK) for confirmation testing. The participants were advised to contact designated local staff for post-test counseling, test results, and appropriate referrals (e.g., outpatient treatment clinics). This testing procedure took approximately 4 weeks.

\section{Measures}

Outcomes were HIV positivity and needle-syringe sharing behaviors. HIV positivity was diagnosed by the abovedescribed blood testing. Needle-syringe sharing behaviors were obtained through self-report. These behaviors, including giving and receiving injection equipment, were queried for two different time frames: last 6 months and last month prior to the study.

Independent variables used to evaluate HIV positivity were demographic characteristics and lifetime behaviors. These included residential area (i.e., study site), age, ethnicity, education, duration of injection drug use, and receiving or giving used needles and/or syringes in the participant's lifetime. Independent variables for needle-syringe sharing behaviors included demographic characteristics and relevant factors suggested by previous studies. These were study site, age, ethnicity, education, duration of injection drug use, frequency of injection drug use in the previous month, going to a hotspot in the previous week, and receiving free clean needles and syringes in the previous 6 months. All behavioral measures (e.g., for drug use and sexual activities) were adapted from internationally standardized questionnaires [19].

We tested the potential associations of several risk factors with different needle-syringe sharing behaviors based on their potential implications for future behavioral interventions. We first examined the factors associated with receiving or giving used needles and/or syringes to gain an overall understanding of risk factors for those behaviors. We then separately examined the preventable behavior of receiving used needles and/ or syringes and its associated factors among HIV-negative MWID because this behavior would place those men at risk for HIV infection and could subsequently increase HIV incidence. Finally, we investigated the behavior of giving used needles and/or syringes and its associated factors among HIVpositive MWID because this practice could transmit the virus to HIV-negative MWID. We examined the behavior of giving and the behavior of receiving separately because interventions to modify these two behaviors target different populations and require different theoretical constructs.

\section{Analysis}

We first explored sociodemographic and behavioral characteristics of the study population across the three study sites. Univariable logistic regression was used to assess the associations between the dependent and independent variables. We then performed multivariable logistic regression models to provide adjusted association estimates. Independent variables were selected for inclusion into multivariable models based on a priori knowledge and their potential associations with the dependent variables in univariable analyses ( $p$ value $<0.25$, as suggested by Hosmer and Lemeshow) [20]. Significance level was determined at 0.05 . We used SAS 9.4 software (SAS, Cary, $\mathrm{NC)}$ to perform all analyses.

\section{Results}

\section{Sample characteristics}

Seven hundred eighty-five MWID were recruited into the study. Those from Bat Xat were the most ethnically diverse, and those in Lao Cai City were primarily of Kinh ethnicity (91.3\%) (Table 1). Sixty-five percent of the participants in Tuan Giao were of Thai ethnicity. The frequency of injection drug use in the previous month was substantially different across the study sites. We found approximately $9 \%$ of the participants in Tuan Giao or Lao Cai City giving or receiving used needles and/or syringes in the previous 6 months, 27.8\% in Bat Xat. Lao Cai City had the most participants going to hotspots in the previous week (80.2\%), compared with Bat Xat (61.0\%) and in Tuan Giao (34.4\%). More than half $(58.2 \%)$ of the participants reported having no sex partners in the previous 6 months. Among those who had one or more sex partners, only 70 participants responded to questions on condom use with irregular 


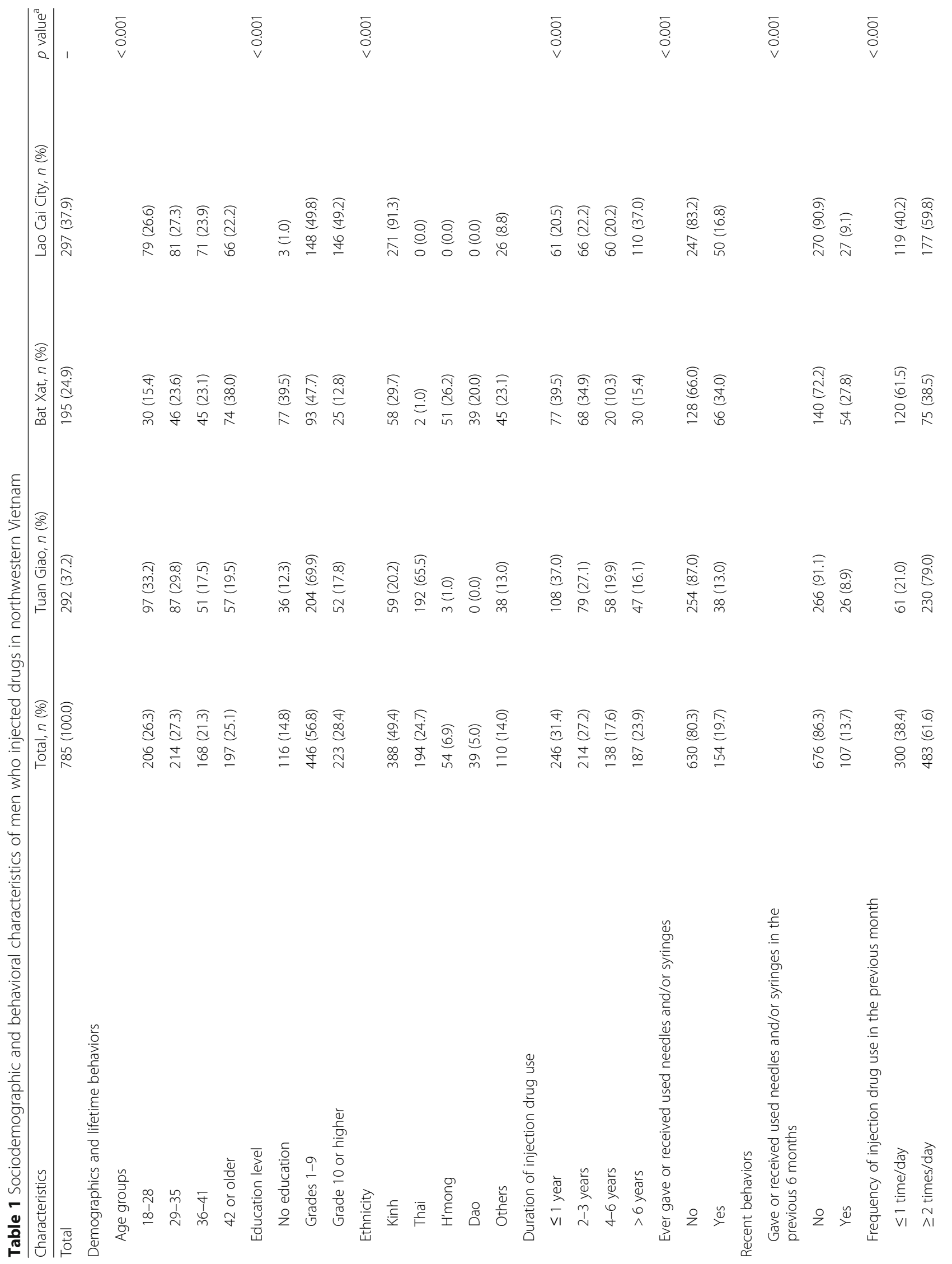




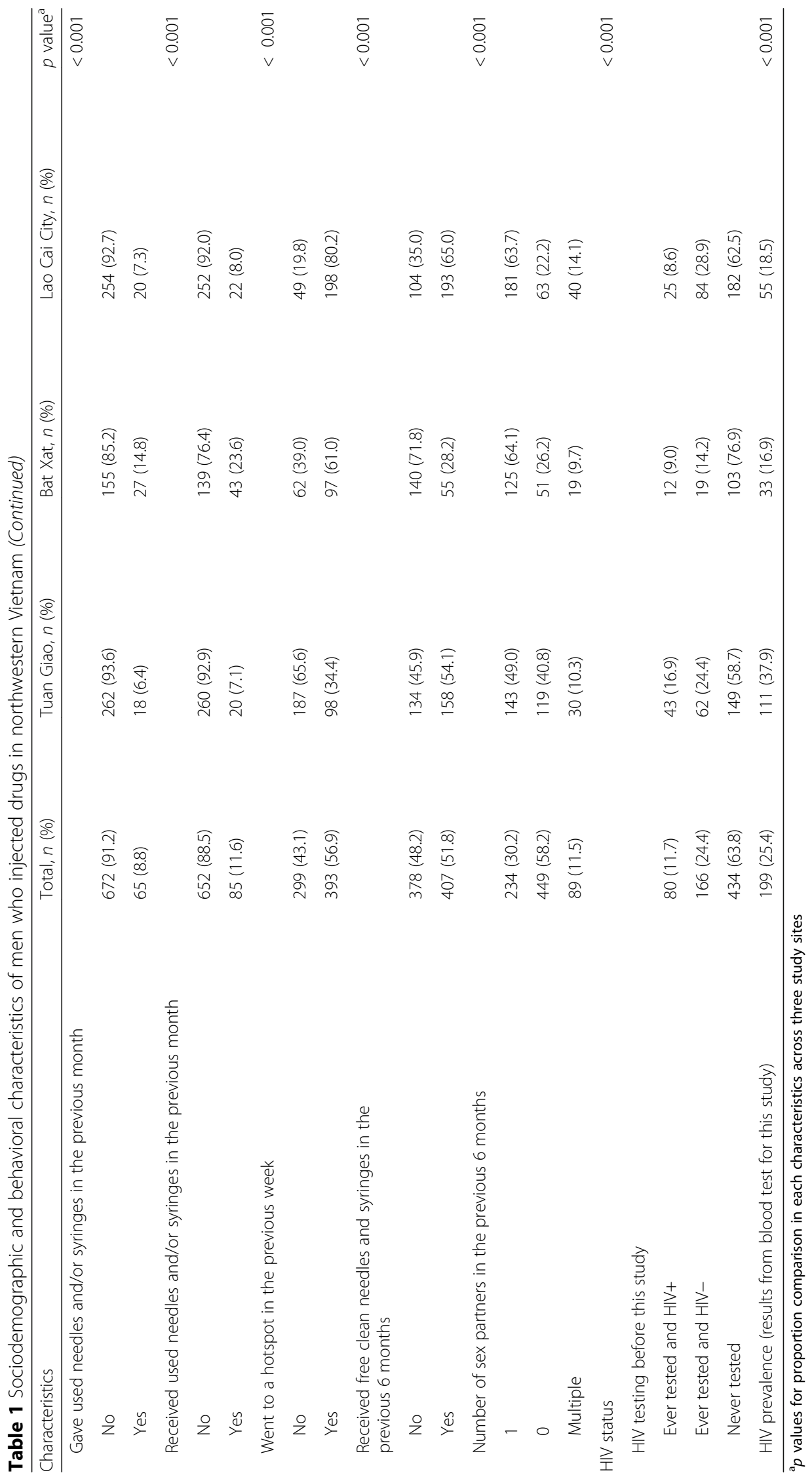


sexual partners. Therefore, we did not examine sexual behaviors in the subsequent analyses. Almost two thirds of the participants had not been tested for HIV before this study, Tuan Giao participants having the highest rate of not having been tested for HIV (58.7\%).

\section{HIV prevalence and associated factors}

The overall HIV prevalence was 25.4\%; 37.9, 16.9, and $18.5 \%$ for Tuan Giao, Bat Xat, and Lao Cai City, respectively. Among the HIV-positive MWID, 59.8\% had never been tested before this study. In addition, of those who had never been tested, $23 \%$ were HIV positive.

Age, ethnicity, and duration of injection drug use were associated with HIV positivity both in univariate analyses and in the adjusted analysis (Table 2). Compared with the youngest age group (18-28 years), those $29-35$ years old were more likely to be HIV positive (adjusted odds ratio $[\mathrm{AOR}]=1.62,95 \%$ confidence interval $[\mathrm{CI}] 1.10-2.60)$, yet participants in the oldest age group ( $\geq 42$ years) were less likely to be HIV positive (AOR $=0.46,95 \%$ CI $0.25-0.83$ ). Participants of Thai ethnicity had higher odds of being HIV positive (AOR $=3.55,95 \% \mathrm{CI} 1.84-6.87$ ) than the Kinh. The MWID with longer duration of injection drug use had higher odds of being HIV positive. We did not examine recent behaviors in the multivariable analysis because temporal relationships between these behaviors and HIV positivity could not be determined; thus, the results would not be interpretable.

\section{Needle-syringe sharing behaviors among MWID}

Table 3 shows factors associated with needle-syringe sharing (receiving or giving used needles, and/or syringes or both) in the previous 6 months among the MWID who had never been tested for HIV before our study. In the adjusted analysis, older participants were less likely to share needle-syringe in the previous 6 months than were 18- to 28-year-olds. However, the oldest participants ( $\geq 42$ years) had similar needle-syringe sharing behaviors in the previous 6 months as the youngest group. Compared with participants who injected drugs for $\leq 1$ year, those who had injected for a longer time (2-3 years and 4-6 years) were more likely to have received or given used needles and/or syringes in the previous 6 months (AOR range 2.62-4.29). Going to a hotspot in the previous week was associated with increased odds of receiving or giving used needles and syringes in the previous 6 months (AOR $=2.81,95 \% \mathrm{CI}$ 1.34-5.90).

Table 4 displays factors associated with receiving used needles and/or syringe in the previous month among HIV-negative participants. In the adjusted model, those who went to a hotspot in the previous week were more likely to receive used needles and/or syringes $(\mathrm{AOR}=3.03 ; 95 \%$ CI $1.28-7.19)$.
Table 5 reports the factors associated with giving used needles and/or syringes in the previous month among the HIV-positive MWID. Going to a hotspot in the previous week increased the odds of giving used needles and/or syringes in the previous month (AOR $=4.57 ; 95 \%$ CI 1.08-19.26). Meanwhile, receiving free clean needles and syringes was associated with reduced odds of giving used needles and/or syringes (AOR $=0.21 ; 95 \%$ CI 0.06-0.79).

Overall, we saw several consistent needle-syringe sharing behavioral patterns. The frequency of injection drug use and ever having been tested for HIV before our study were not associated with any of the needle-syringe sharing behaviors examined (Tables 3, 4, and 5). Lastly, there was no significant difference in the sharing behaviors across the four ethnic groups-Kinh, Thai, H'mong, and Dao.

\section{Discussion}

To our best knowledge, this study is among only a few studies that examined the prevalence of HIV infection among the MWID in the northwestern area of Vietnam, and this is the first study to examine correlates of HIV infection and of needle-syringe sharing behaviors in this population. We found three key points: first, HIV prevalence among MWID was significantly different across ethnicities. Second, a large number of the MWID had not been tested for HIV before this study, and the HIVpositive MWID who received free clean needles and syringes were less likely to give their used needles and syringes to peers. Third, going to a hotspot in the previous week emerged as a salient factor associated with the needle-syringe sharing behaviors.

To the first point, Thai ethnicity MWID had a significantly higher prevalence of infection than the other groups. On the one hand, further research is needed to investigate why there are such health disparities. This type of research could help reduce HIV incidence and ensure that similar disparities do not exist in the subsequent HIV/AIDS care continuum. On another side, prevention efforts should focus on maintaining HIVnegative status among MWID of other ethnicities with low HIV prevalence (including Kinh, H'mong, and Dao). Additionally, it is imperative to design and conduct effective prevention programs that suit this ethnically diverse area. For example, health promotion messages should be culturally and linguistically appropriate [21]. Bui and colleagues found that residents of areas with several different ethnicities had low awareness of HIV [22]. If this low awareness is also true for MWID in our study area, there would be demand for interventions to improve HIV-related awareness, knowledge, and attitudes.

We compared our results for Tuan Giao with the results from the most recent HIV/sexually transmitted infections (STI) IBBS report in Vietnam [23]. This IBBS 
Table 2 Associations between HIV infection and sociodemographic or behavioral characteristics among men who injected drugs in northwestern Vietnam

\begin{tabular}{|c|c|c|c|c|c|}
\hline \multirow[t]{2}{*}{ Characteristics } & \multicolumn{5}{|c|}{ HIV positivity } \\
\hline & $n\left(\%^{a}\right)$ & Unadjusted OR (95\% Cl) & $p$ value & Adjusted OR $(95 \% \mathrm{Cl})^{\mathrm{b}}$ & $p$ value \\
\hline \multicolumn{6}{|l|}{ Study sites } \\
\hline Tuan Giao & $111(38.0)$ & 1 & & 1 & \\
\hline Bat Xat & $33(16.9)$ & $0.33(0.26-0.52)$ & $<0.001$ & $1.44(0.75-2.79)$ & 0.278 \\
\hline Lao Cai City & $55(18.5)$ & $0.37(0.26-0.54)$ & $<0.001$ & $0.74(0.40-1.36)$ & 0.329 \\
\hline \multicolumn{6}{|l|}{ Demographics and lifetime behaviors } \\
\hline \multicolumn{6}{|l|}{ Age groups } \\
\hline $18-28$ & $52(25.2)$ & 1 & & 1 & \\
\hline $29-35$ & $80(37.4)$ & $1.77(1.16-2.69)$ & 0.008 & $1.62(1.10-2.60)$ & 0.046 \\
\hline $36-41$ & $37(22.0)$ & $0.84(0.52-1.35)$ & 0.467 & $0.64(0.36-1.12)$ & 0.116 \\
\hline 42 or older & $30(15.2)$ & $0.53(0.32-0.88)$ & 0.013 & $0.46(0.25-0.83)$ & 0.010 \\
\hline \multicolumn{6}{|l|}{ Ethnicity } \\
\hline Kinh & $81(20.9)$ & 1 & & & \\
\hline Thai & $90(46.4)$ & $3.28(2.26-4.77)$ & $<0.001$ & $3.55(1.84-6.87)$ & $<0.001$ \\
\hline H'mong & $1(1.9)$ & $0.07(0.01-0.53)$ & 0.010 & $0.07(0.01-0.61)$ & 0.016 \\
\hline Dao & $3(7.7)$ & $0.316(0.095-1.052)$ & 0.060 & $0.34(0.08-1.42)$ & 0.140 \\
\hline Others & $24(21.8)$ & $1.058(0.632-1.769)$ & 0.831 & $0.89(0.48-1.64)$ & 0.707 \\
\hline \multicolumn{6}{|l|}{ Education level } \\
\hline No education & $22(19.0)$ & 1 & & 1 & \\
\hline Grades 1-9 & $141(31.6)$ & $1.98(1.19-3.27)$ & 0.008 & $0.99(0.50-1.95)$ & 0.969 \\
\hline Grade 10 or higher & $36(16.1)$ & $0.82(0.458-1.48)$ & 0.513 & $0.46(0.21-1.02)$ & 0.055 \\
\hline \multicolumn{6}{|l|}{ Duration of injection drug use } \\
\hline$\leq 1$ year & $38(15.5)$ & 1 & & 1 & \\
\hline $2-3$ years & $51(23.8)$ & $1.71(1.07-2.73)$ & 0.024 & $2.15(1.26-3.65)$ & 0.005 \\
\hline $4-6$ years & $50(36.2)$ & $3.11(1.91-5.08)$ & $<0.001$ & $4.36(2.46-7.73)$ & $<0.001$ \\
\hline$>6$ years & $60(32.1)$ & $2.59(1.63-4.11)$ & $<0.001$ & $5.63(3.10-10.26)$ & $<0.001$ \\
\hline \multicolumn{6}{|l|}{ Ever gave or received used needles and/or syringes } \\
\hline No & $163(25.9)$ & 1 & & & \\
\hline Yes & $36(23.4)$ & $0.87(0.58-1.32)$ & 0.524 & & \\
\hline \multicolumn{6}{|l|}{ Recent behaviors } \\
\hline Frequency of injection drug use in the previous month & & & & - & \\
\hline$\leq 1$ time/day & $59(19.7)$ & 1 & & - & \\
\hline$\geq 2$ times/day & $140(29.0)$ & $1.67(1.18-2.36)$ & 0.004 & - & \\
\hline Gave or received used needles and/or syringes in the previous 6 months & & & & - & \\
\hline No & $182(26.9)$ & 1 & & & \\
\hline Yes & $17(15.9)$ & $0.51(0.30-0.89)$ & 0.017 & & \\
\hline Gave used needles and/or syringes in the previous month & & & & - & \\
\hline No & $166(24.7)$ & 1 & & - & \\
\hline Yes & $14(21.5)$ & $0.84(0.45-1.55)$ & 0.571 & - & \\
\hline Received used needles and/or syringes in the previous month & & & & - & \\
\hline No & $164(25.2)$ & 1 & & - & \\
\hline Yes & $16(18.8)$ & $0.69(0.39-1.22)$ & 0.204 & - & \\
\hline
\end{tabular}


Table 2 Associations between HIV infection and sociodemographic or behavioral characteristics among men who injected drugs in northwestern Vietnam (Continued)

\begin{tabular}{|c|c|c|c|c|}
\hline \multirow[t]{2}{*}{ Characteristics } & \multicolumn{4}{|c|}{ HIV positivity } \\
\hline & $n\left(\%^{a}\right)$ & Unadjusted OR (95\% Cl) & $p$ value & Adjusted OR $(95 \% \mathrm{Cl})^{\mathrm{b}} p$ value \\
\hline Went to a hotspot in the previous week & & & & - \\
\hline No & $101(33.8)$ & 1 & & - \\
\hline Yes & $76(19.3)$ & $0.47(0.33-0.67)$ & $<0.001$ & - \\
\hline Received free clean needles and syringes in the previous 6 months & & & & - \\
\hline No & $90(23.8)$ & 1 & & - \\
\hline Yes & $109(26.8)$ & $1.17(0.85-1.62)$ & 0.339 & - \\
\hline Number of sex partners in the previous 6 months & & & & - \\
\hline 1 & $67(28.6)$ & 1 & & - \\
\hline 0 & $116(25.8)$ & $0.87(0.61-1.24)$ & 0.434 & - \\
\hline Multiple & $14(15.7)$ & $0.47(0.25-0.88)$ & 0.019 & - \\
\hline
\end{tabular}

$O R$ odds ratio, $\mathrm{Cl}$ confidence interval

a Percent by $n$ in each category of sociodemographic or behavioral characteristics

${ }^{\mathrm{b}}$ In the multivariable model, there were 199 HIV-positive and 586 HIV-negative participants

report provided findings from the data collected in 2013 and trend analyses comprising the findings from the data collected in 2005 and 2009. Of note, this report provided aggregated data for the people who injected drugs from three study sites in Dien Bien province, one of which was Tuan Giao. In our study, we found that HIV prevalence in Tuan Giao was 37.9\%; this is consistent with the IBBS's decreasing HIV trend for Dien Bien province, from $57 \%$ in 2006 to $31 \%$ in 2013 . Our study also corroborated IBBS's statistics with respect to HIV testing. In Dien Bien province, HIV testing rates increased from $25 \%$ in 2009 to $48 \%$ in 2013. In Tuan Giao, we found the 2011 rate of ever having had an HIV test was 41.3\%.

The rates of ever having been tested for HIV before this study in Bat Xat (23.1\%) and Lao Cai (37.5\%) were lower than the median HIV testing rate (38\%) from a 10-province survey of MWID conducted in 2009-2010 [24]. Of note, many of these 10 provinces (including Hanoi, Hai Phong, Quang Ninh, Nghe An, and Ho Chi Minh City) had received technical and financial support from large donors for HIV/AIDS control programs (e.g., The US President's Emergency Plan for HIV/AIDS Relief and The Global Fund to Fight AIDS, Tuberculosis, and Malaria). This support might have contributed to better HIV testing rates. The rate of MWID in Tuan Giao who had ever been tested for HIV before our study was $41.3 \%$, the highest among our three study sites; however, this rate was still lower than rates seen in several of the 10 provinces surveyed [24]. By contrast, in 2009, $80 \%$ of people who injected drugs from 20 cities in the USA reported to have had at least one HIV test during their lifetime [25]. In addition, people who inject drugs in the USA are recommended to have HIV screening annually or more often [26].
Given the low rates of HIV testing among our participants, it is imperative for policymakers to focus resources to improve HIV testing uptake among MWID. Previous studies have demonstrated that HIV testing programs were highly cost-effective in that they averted a large number of HIV infections thereby reducing the economic burden associated with these infections [27, 28]. In addition, improving HIV testing uptake will lead to better reach and coverage of subsequent HIV/AIDS care services because testing is considered a care sequence entry [29]. HIV testing programs may link participants to such services as self-help groups to maintain HIV-negative status or outpatient treatment for HIVpositive MWID. High rates of HIV testing are an important component for reaching the WHO 90-90-90 goals. We found that ever having been tested for HIV before this study was not associated with any of the needle-syringe sharing behaviors. This finding was in agreement with Do and colleagues' study among people who injected drugs and had known and unknown HIVpositive status [3]. However, our finding contradicted those of Bergenstrom and colleagues from their northern Vietnam study, which showed that most people living with HIV/AIDS had adjusted their injection practices once they learned they were HIV positive [30]. That ever having been tested for HIV was not associated with needle-syringe sharing behaviors across studies may be explained by the low numbers of those who actually received the results of their HIV testing. Poor post-test counseling might also have contributed to this finding. Without appropriate counseling, MWID might have not been referred to support groups that provide psychological aid (e.g., raising awareness, peer-motivation) or access to free syringes and needles [31]. 
Table 3 Factors associated with receiving or giving used needles and/or syringes in the previous 6 months among men who injected drugs in northwestern Vietnam and had never been tested for HIV before this study

\begin{tabular}{|c|c|c|c|c|c|}
\hline \multirow[t]{2}{*}{ Characteristics } & \multirow[b]{2}{*}{$n\left(\%^{\mathrm{a}}\right)$} & \multicolumn{4}{|c|}{ Received or gave used needles and/or syringes in the previous 6 months } \\
\hline & & Unadjusted OR (95\% Cl) & $p$ value (for trend) & Adjusted OR $(95 \% \mathrm{Cl})$ & $p$ value (for trend) \\
\hline \multicolumn{6}{|l|}{ Study sites } \\
\hline Tuan Giao & $144(38.6)$ & 1 & & 1 & \\
\hline Bat Xat & $82(22.0)$ & $2.41(1.21-4.79)$ & 0.012 & $1.22(0.43-3.44)$ & 0.706 \\
\hline Lao Cai City & $147(39.4)$ & $0.69(0.33-1.44)$ & 0.325 & $0.58(0.18-1.92)$ & 0.373 \\
\hline Age groups & & & $(0.345)$ & & $(0.060)$ \\
\hline $18-28$ & $92(24.7)$ & 1 & & 1 & \\
\hline $29-35$ & 109 (29.2) & $0.66(0.31-1.39)$ & 0.271 & $0.40(0.17-0.95)$ & 0.037 \\
\hline $36-41$ & $89(23.9)$ & $0.46(0.20-1.09)$ & 0.079 & $0.25(0.09-0.68)$ & 0.007 \\
\hline 42 or older & $83(22.3)$ & $0.76(0.35-1.67)$ & 0.500 & $0.45(0.17-1.17)$ & 0.101 \\
\hline \multicolumn{6}{|l|}{ Ethnicity } \\
\hline Kinh & $173(46.4)$ & 1 & & 1 & \\
\hline Thai & $96(25.7)$ & $1.14(0.50-2.47)$ & 0.790 & $1.12(0.31-4.13)$ & 0.862 \\
\hline H'mong & $16(4.3)$ & $3.91(1.22-12.54)$ & 0.022 & $4.07(0.83-20.06)$ & 0.085 \\
\hline Dao & $21(5.6)$ & $4.31(1.54-12.06)$ & 0.006 & $4.59(0.96-21.89)$ & 0.056 \\
\hline Others & $67(18.0)$ & $2.28(1.06-4.89)$ & 0.035 & $2.25(0.84-6.05)$ & 0.108 \\
\hline Education level & & & $(0.014)$ & & $(0.370)$ \\
\hline No education & $43(11.5)$ & 1 & & 1 & \\
\hline Grades 1-9 & $224(60.1)$ & $0.52(0.24-1.13)$ & 0.099 & $1.06(0.38-2.94)$ & 0.912 \\
\hline Grade 10 or higher & $106(28.4)$ & $0.30(0.12-0.78)$ & 0.013 & $0.79(0.22-2.81)$ & 0.712 \\
\hline Duration of injection drug use & & & $(0.634)$ & & $(0.061)$ \\
\hline$\leq 1$ year & $126(33.8)$ & 1 & & 1 & \\
\hline $2-3$ years & $100(26.8)$ & $2.04(0.95-4.36)$ & 0.067 & $2.62(1.09-6.30)$ & 0.032 \\
\hline $4-6$ years & $71(19.0)$ & $2.33(1.04-5.23)$ & 0.041 & $4.29(1.65-11.19)$ & 0.003 \\
\hline$>6$ years & $76(20.4)$ & $1.02(0.40-2.59)$ & 0.962 & $2.68(0.85-8.47)$ & 0.093 \\
\hline \multicolumn{6}{|c|}{ Frequency of injection drug use in the previous month } \\
\hline$\leq 1$ time/day & $141(37.8)$ & 1 & & 1 & \\
\hline$\geq 2$ times/day & $232(62.2)$ & $0.75(0.42-1.34)$ & 0.335 & $0.77(0.38-1.55)$ & 0.457 \\
\hline \multicolumn{6}{|c|}{ Went to a hotspot in the previous week } \\
\hline No & $155(41.6)$ & 1 & & 1 & \\
\hline Yes & $218(58.5)$ & $2.10(1.13-3.95)$ & 0.022 & $2.81(1.34-5.90)$ & 0.006 \\
\hline \multicolumn{6}{|c|}{ Received free clean needles and syringes in the previous 6 months } \\
\hline No & $186(49.9)$ & 1 & & 1 & \\
\hline Yes & $187(50.1)$ & $0.57(0.32-1.01)$ & 0.057 & $0.63(0.31-1.28)$ & 0.201 \\
\hline
\end{tabular}

$O R$ odds ratio, $\mathrm{Cl}$ confidence interval

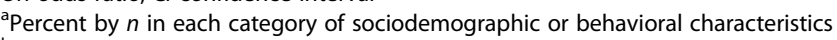

${ }^{b}$ In the multivariable model, there were 55 participants who received used needles and/or syringes and 318 participants who did not

Our study showed that access to free syringes and needles would contribute to elimination of HIV transmission by infected MWID. Among the HIV-positive participants, those who received free clean needles and syringes were less likely to give their used needles and syringes to peers. Evidence from an eight-year project in Vietnam's Lang Son province (bordering China), needle and syringe provision was one of the interventions that helped control the HIV epidemics among injection drug users [19]. Also, the World Health Organization (WHO)'s recommended needle and syringe programs as one of the nine service components in a comprehensive package to prevent and control HIV/AIDS among injection drug users. The remaining eight components include opioid substitution 
Table 4 Factors associated with receiving used needles and/or syringes in the previous month among HIV-negative men who injected drugs in northwestern Vietnam

\begin{tabular}{|c|c|c|c|c|c|}
\hline \multirow[t]{2}{*}{ Characteristics } & \multirow[b]{2}{*}{$n\left(\%^{a}\right)$} & \multicolumn{4}{|c|}{ Received used needles and/or syringes in the previous month } \\
\hline & & Unadjusted OR (95\% Cl) & $p$ value (for trend) & Adjusted $\mathrm{OR}^{\mathrm{b}}(95 \% \mathrm{Cl})$ & $p$ value (for trend) \\
\hline \multicolumn{6}{|l|}{ Study sites } \\
\hline Tuan Giao & $146(35.8)$ & 1 & & 1 & \\
\hline Bat Xat & $79(19.4)$ & $3.12(1.37-7.11)$ & 0.007 & $1.70(0.47-6.17)$ & 0.417 \\
\hline Lao Cai City & $182(44.7)$ & $1.02(0.45-2.33)$ & 0.957 & $1.13(0.33-3.94)$ & 0.848 \\
\hline Age groups & & & $(0.458)$ & & \\
\hline $18-28$ & $104(25.6)$ & 1 & & - & \\
\hline $29-35$ & $97(23.8)$ & $1.08(0.43-2.72)$ & 0.870 & - & \\
\hline $36-41$ & $101(24.8)$ & $0.81(0.31-2.14)$ & 0.669 & - & \\
\hline 42 or older & $105(25.8)$ & $1.33(0.56-3.18)$ & 0.524 & - & \\
\hline \multicolumn{6}{|l|}{ Ethnicity } \\
\hline Kinh & $233(57.3)$ & 1 & & 1 & \\
\hline Thai & $77(18.9)$ & $1.45(0.57-3.71)$ & 0.434 & $2.91(0.73-11.51)$ & 0.129 \\
\hline H'mong & $16(3.9)$ & $6.61(2.03-21.49)$ & 0.002 & $5.19(0.89-30.41)$ & 0.068 \\
\hline Dao & $20(4.9)$ & $4.84(1.55-15.14)$ & 0.007 & $3.18(0.56-18.06)$ & 0.191 \\
\hline Others & $61(15.0)$ & $2.52(1.04-6.06)$ & 0.040 & $3.01(1.08-8.38)$ & 0.035 \\
\hline Education level & & & $(0.002)$ & & $(0.189)$ \\
\hline No education & $38(9.3)$ & 1 & & 1 & \\
\hline Grades 1-9 & $223(54.8)$ & $0.31(0.13-0.71)$ & 0.006 & $0.66(0.21-2.09)$ & 0.484 \\
\hline Grade 10 or higher & $146(35.9)$ & $0.18(0.07-0.49)$ & 0.001 & $0.51(0.13-2.02)$ & 0.336 \\
\hline Duration of injection drug use & & & $(0.383)$ & & $(0.059)$ \\
\hline$\leq 1$ year & $142(34.9)$ & 1 & & 1 & \\
\hline $2-3$ years & $102(25.1)$ & $2.16(0.89-5.26)$ & 0.091 & $2.13(0.78-5.81)$ & 0.142 \\
\hline $4-6$ years & $67(16.5)$ & $2.90(1.14-7.39)$ & 0.025 & $3.83(1.32-11.13)$ & 0.014 \\
\hline$>6$ years & $96(23.6)$ & $1.34(0.50-3.61)$ & 0.559 & $2.52(0.78-8.19)$ & 0.125 \\
\hline \multicolumn{6}{|c|}{ Frequency of injection drug use in the previous month } \\
\hline$\leq 1$ time/day & $152(37.4)$ & 1 & & 1 & \\
\hline$\geq 2$ times/day & $255(62.7)$ & $0.66(0.35-1.27)$ & 0.211 & $0.69(0.31-1.51)$ & 0.347 \\
\hline \multicolumn{6}{|c|}{ Went to a hotspot in the previous week } \\
\hline No & $155(38.1)$ & 1 & & 1 & \\
\hline Yes & $252(61.9)$ & $2.36(1.09-5.09)$ & 0.029 & $3.03(1.28-7.19)$ & 0.012 \\
\hline \multicolumn{6}{|c|}{ Received free clean needles and syringes in the previous 6 months } \\
\hline No & $187(46.0)$ & 1 & & - & \\
\hline Yes & $220(54.1)$ & $0.79(0.41-1.51)$ & 0.476 & - & \\
\hline \multicolumn{6}{|l|}{ Ever tested for HIV } \\
\hline No & $265(65.1)$ & 1 & & 1 & \\
\hline Yes & $142(34.9)$ & $0.57(0.27-1.20)$ & 0.141 & $0.93(0.40-2.13)$ & 0.862 \\
\hline
\end{tabular}

$O R$ odds ratio, $\mathrm{Cl}$ confidence interval

apercent by $n$ in each category of sociodemographic or behavioral characteristics

${ }^{\mathrm{b}}$ In the multivariable model, there were 41 participants who received used needles and/or syringes and 366 participants who did not

therapy and other drug dependence treatment; HIV testing and counseling; antiretroviral therapy; prevention and treatment of STIs; condom programs for injection drug users and their sexual partners; targeted information, education, and communication for injection drug users and their sexual partners; vaccination, diagnosis, and treatment of viral hepatitis; and prevention, diagnosis, and treatment of tuberculosis [32]. It is urgent to scale up free 
Table 5 Factors associated with giving used needles and/or syringes in the previous month among HIV-positive men who injected drugs in northwestern Vietnam

\begin{tabular}{|c|c|c|c|c|c|}
\hline \multirow[b]{2}{*}{ Variables } & \multirow[b]{2}{*}{$n(\%)^{a}$} & \multicolumn{4}{|c|}{ Gave used needles and/or syringes in the previous month } \\
\hline & & Unadjusted OR (95\% Cl) & $p$ value (for trend) & Adjusted OR ${ }^{\mathrm{b}}(95 \% \mathrm{Cl})$ & $p$ value \\
\hline \multicolumn{6}{|l|}{ Study sites } \\
\hline Tuan Giao & $104(57.8)$ & 1 & & 1 & \\
\hline Bat Xat & $28(15.6)$ & $1.52(0.28-8.30)$ & 0.627 & $0.37(0.04-3.72)$ & 0.395 \\
\hline Lao Cai City & $48(26.7)$ & $3.38(1.01-11.27)$ & 0.047 & $2.75(0.72-10.56)$ & 0.140 \\
\hline Age groups & & & $(0.120)$ & & \\
\hline $18-28$ & $49(27.2)$ & 1 & & - & \\
\hline $29-35$ & $72(40.0)$ & $0.54(0.15-1.86)$ & 0.325 & - & \\
\hline $36-41$ & $33(18.3)$ & $0.46(0.09-2.45)$ & 0.364 & - & \\
\hline 42 or older & $26(14.4)$ & $0.29(0.03-2.52)$ & 0.260 & - & \\
\hline \multicolumn{6}{|l|}{ Ethnicity } \\
\hline Kinh & $70(38.9)$ & 1 & & - & \\
\hline Thai & $85(47.2)$ & $0.22(0.04-1.08)$ & 0.062 & - & \\
\hline H'mong & $1(0.6)$ & $-^{c}$ & - & - & \\
\hline Dao & $3(1.7)$ & $-^{c}$ & - & - & \\
\hline Others & $21(11.7)$ & $1.50(0.35-6.40)$ & 0.584 & - & \\
\hline Education level & & & $(0.623)$ & & \\
\hline No education & $20(11.1)$ & 1 & & - & \\
\hline Grades 1-9 & $130(72.2)$ & $0.83(0.17-4.06)$ & 0.820 & - & \\
\hline Grade 10 or higher & $30(16.7)$ & $0.31(0.03-3.68)$ & 0.354 & - & \\
\hline Duration of injection drug use & & & $(0.194)$ & & \\
\hline$\leq 1$ year & $37(20.6)$ & 1 & & - & \\
\hline 2-3 years & $45(25.0)$ & $0.81(0.11-6.08)$ & 0.841 & - & \\
\hline $4-6$ years & $47(26.1)$ & $2.08(0.38-11.41)$ & 0.398 & - & \\
\hline$>6$ years & $51(28.3)$ & $1.90(0.35-10.39)$ & 0.458 & - & \\
\hline \multicolumn{6}{|l|}{ Frequency of injection drug use } \\
\hline$\leq 1$ time/day & $52(28.9)$ & 1 & & - & \\
\hline$\geq 2$ times/day & $128(71.1)$ & $1.54(0.41-5.75)$ & 0.524 & - & \\
\hline \multicolumn{6}{|c|}{ Went to a hotspot in the previous week } \\
\hline No & $65(40.6)$ & 1 & & 1 & \\
\hline Yes & $95(59.4)$ & $5.58(1.47-21.14)$ & 0.012 & $4.57(1.08-19.26)$ & 0.039 \\
\hline \multicolumn{6}{|c|}{ Received free clean needles and syringes in the previous 6 months } \\
\hline No & $100(55.6)$ & 1 & & 1 & \\
\hline Yes & $80(44.4)$ & $0.29(0.09-0.97)$ & 0.044 & $0.21(0.06-0.79)$ & 0.021 \\
\hline \multicolumn{6}{|l|}{ Ever tested for HIV } \\
\hline No & $98(58.7)$ & 1 & & - & \\
\hline Yes & $69(41.3)$ & $0.61(0.18-2.06)$ & 0.425 & - & \\
\hline
\end{tabular}

OR odds ratio, $\mathrm{Cl}$ confidence interval

a Percent by $n$ in each category of sociodemographic or behavioral characteristics

${ }^{\mathrm{b}}$ In the multivariable model, there were 13 participants who gave used needles and/or syringes and 146 participants who did not

${ }^{c}$ Could not be computed because the number in this subgroup who injected drugs and gave used needles and syringes in the previous month was small or none

access to clean needles and syringes for the HIVpositive MWIDs in this region. As mentioned, the HIV testing rate among this group was low. Altogether, we recommend future HIV/AIDS interventions extensively offering free needles and syringes to the MWID in the region regardless of the HIV status. 
In the northwest region, a low-resourced area, it is imperative to prioritize HIV testing and needle and syringe provision programs among the recommended WHO services components. Adding other service components will be contingent upon budget availability. At the time of the data collection, there were no methadone maintenance treatment (MMT) programs in Dien Bien and Lao Cai provinces. Previous studies showed MMT programs improved the referral and testing uptake among Vietnamese drug users and their partners [33], and ultimately these programs helped lower the healthcare costs in the long term [34]. Hence, policymakers and HIV/AIDS program implementers in the region may consider adding MMT programs as the next priority service component for the MWID.

The rate of MIWD who were sexually active in our study $(42 \%)$ is within the range found in previous studies. In a study in Hai Phong, a northern city of Vietnam, 31\% of the MWID were sexually active during the previous 3 months [35]. Go and colleagues found that $73 \%$ of the MWID in Bac Ninh, a northern province, were sexually active during the previous 6 months [36]. Also, one half to two thirds of the MWID in the border areas-Lang Son Province (Vietnam) and Ning Ming County (China)-reported being sexually active during the previous 6 months [37].

Going to a hotspot was an important factor because it was consistently associated with an increased likelihood of needle-syringe sharing behaviors in all subgroups (including MWID who had never been tested for HIV before this study and HIV-negative and HIV-positive MWID). Our finding corroborated the results of several studies that showed injecting drugs together with other users, injecting at hotspots, and injecting on the street or in public areas increased sharing of needles and syringes $[1,3]$. Hotspots have been suggested to be an effective venue to deliver harm reduction programs (e.g., clean needle and syringe distribution and exchange) [38]. Therefore, policymakers and implementers of HIV/ AIDS intervention programs might find greater impact if they target hotspots first.

We succeeded in recruiting a large sample of the MWID thanks to a well-organized preparation. Prior to designing the study, the research team spent multiple site visits learning about the MWID in the region. We established a productive rapport with the local authorities leading the HIV/AIDS response and with key peer educators (knowledgeable about numerous MWIDs and familiar with traveling across complex geographic areas.) Also, during these visits, the research team carefully arranged logistical preparation, i.e., identifying appropriate locations for the data collection that were the most accessible to potential study participants.
However, our study is not without limitations. Although the literature suggests that sexual and injection behaviors are strongly associated with HIV risk [3, 4], we could not account for the influence of sexual behaviors because our participants had a low rate of response to questions on sexual behaviors. Without accounting for this factor, our study may overestimate the associations between risk factors and HIV positivity or needle-syringe sharing behaviors. Previous studies also showed that HIV knowledge was an important predictor of HIV infection among people living in ethnic minority areas [22, 39]; however, this type of data was not available in our study. Future research may focus on exploring the link between HIV knowledge and risky injection behaviors among our MWID study population to better explain the complex HIV/AIDS epidemic in northwestern Vietnam. Of the three areas included in our study, Tuan Giao and Lao Cai City were at the same level of the census tract; Bat Xat was one level smaller. However, our previous site visits informed a considerable number of MWID in Bat Xat which was comparable with those in Tuan Giao and Lao Cai City. Therefore, it was reasonable to include Bat Xat in our analysis.

Chain referral sampling method, which is commonly known as one of the most practical and effective ways to reach hidden populations, $[40,41]$ helped us to recruit a large number of MIWD. Nevertheless, this sampling method might introduce some biases to representativeness and subsequent prevalence estimates in our study. We considered statistical adjustments using information on individual network size [42]; however, it was impractical to obtain the precise information. First, the actual network size was constantly changing during the time of data collection due to the anti-drug campaign. Second, estimation of network size and subsequent statistical adjustment require a documentation of individual linkages during the referral process. MWID deemed selfreporting their network information sensitive because they were afraid that law enforcement authorities would discover their connectedness with the drug user community and target other drug users for the anti-drug campaign at that time. Also, in our study, we asked all recruited participants to refer other potential participants (i.e., not just selected a few seeds in a large pool at the beginning and not limited the number of waves); thus, this mitigated the selection bias.

In addition, our results were subject to recall bias because most measures were based on self-report. However, to minimize this bias and better measure recent/current behaviors, we used short time frames (i.e., previous month for the frequency of injection drug use, previous week for going to a hotspot). Furthermore, we used different time frames for the same behaviors (e.g., needle-syringe sharing behaviors in the previous 6 months and the previous 
month) to aid recall and to enable response double checking. Lastly, because HIV infection status and needlesyringe sharing behaviors are sensitive topics, participants' responses might be subject to social desirability bias.

\section{Conclusion}

Our investigation of a subset of the MWID in the northwestern Vietnam found that these MWID of different ethnicities had different risks for HIV infection. To prevent and control an HIV/AIDS epidemic in this region, intervention programs and messages should be tailored to the culture and in the language of each ethnic group. While it is ideal to deliver all nine components of the WHO comprehensive package of HIV prevention, treatment, and care services, we recommend the top two priority services for the MWID in this resource-constrained region. These two services include enhanced HIV testing and needle and syringe provision. Because going to a hotspot was a salient factor associated with needle-syringe sharing behaviors, policymakers and implementers of HIV/AIDS intervention programs should first target such venues in order to achieve greater impact.

\section{Abbreviations}

AIDS: Acquired immune deficiency syndrome; AOR: Adjusted odds ratio; Cl: Confidence interval; HIV: Human immunodeficiency virus; IBBS: Integrated Biological and Behavioral Surveillance; MWID: Men who inject drugs; STI: Sexually transmitted infection

\section{Acknowledgements}

Not applicable.

\section{Funding}

This study was funded in part by US Centers for Disease Control and Prevention contract \#200-2010-33319 awarded to Abt Associates. Van T. Nghiem was supported by the Center for Global Initiatives International Internship Award and HPM Research Travel Fund both from The University of North Carolina at Chapel Hill, and the Vietnam Education Foundation Fellowship. Van T. Nghiem was supported by the Predoctoral Fellowship, Cancer Education, and Career Development Program, National Institute of Health/National Cancer Institute Grant R25 CA57712 (PI: Mullen) and research funding from the Department of Health Promotion and Behavioral Sciences, both from the University of Texas School of Public Health. Thanh C. Bui was supported by a faculty fellowship from The University of Texas MD Anderson Cancer Center, Duncan Family Institute for Cancer Prevention and Risk Assessment, and is supported by a grant from the Oklahoma Tobacco Settlement Endowment Trust, 092-016-0002 (PI: Vidrine).

\section{Availability of data and materials}

The datasets used and/or analyzed during the current study are available from the corresponding author on reasonable request.

\section{Disclaimer}

The content is solely the responsibility of the authors and does not necessarily represent the official views of the US Centers for Disease Control and Prevention, the National Cancer Institute, or the National Institutes of Health.

\section{Authors' contributions}

TMH, SHP, BTK, VTN, and TCB contributed to the research conception and design. SHP, BTK, VTN, and TMH contributed to the collection of data. VTN and TCB contributed to the analysis. VTN, TCB, TMH, PPN, SHP, BTK, and RK contributed to the interpretation of the results. VTN, TCB, TMH, and PPN contributed to the drafting of the manuscript. VTN, TCB, TMH, PPN, SHP, BTK, and RK contributed to the revising and approving of the final manuscript.

\section{Ethics approval and consent to participate}

The Institutional Review Board of Abt Associates and the Ethics Committee of Centers for Disease Control and Prevention in the US, and Hanoi School of Public Health's Ethical Review Board in Vietnam approved the study's research protocol and questionnaires. All of these boards approved oral informed consent because of potential severe consequences for participants if there were a confidentiality breach associated with a written consent.

\section{Consent for publication}

Not applicable.

\section{Competing interests}

The authors declare that they have no competing interests.

\section{Publisher's Note}

Springer Nature remains neutral with regard to jurisdictional claims in published maps and institutional affiliations.

\section{Author details}

'Department of Management, Policy and Community Health, University of Texas Health Science Center at Houston School of Public Health, Houston, TX 77030, USA. ${ }^{2}$ Southwest Oncology Group Statistical Center, Fred Hutchinson Cancer Research Center, Seattle, WA 98109, USA. ${ }^{3}$ Department of Family and Preventive Medicine, University of Oklahoma Health Sciences Center, Oklahoma City, OK 73104, USA. ${ }^{4}$ Division of Global HIV/AIDS, U.S. Centers for Disease Control and Prevention, Hanoi, Vietnam. International Health Division, Abt Associates, Bethesda, MD 20814, USA. ${ }^{6}$ AIDS Healthcare Foundation, Hanoi, Vietnam. ' U.S. Health Division, Abt Associates, Cambridge, MA 02138, USA. ${ }^{8}$ Health Finance and Government Project, Abt Associates, Hanoi, Vietnam.

Received: 13 November 2017 Accepted: 19 January 2018

Published online: 14 February 2018

\section{References}

1. Go VF, Frangakis C, Van Nam L, Sripaipan T, Bergenstrom A, Li F, et al. Characteristics of high-risk HIV-positive IDUs in Vietnam: implications for future interventions. Subst Use Misuse. 2011;46:381-9.

2. Celentano DD, Beyer C. Public health aspects of HIV/AIDS in low and middle income countries. Springer 2008.

3. Do K, Minichiello V, Hussain R. HIV risks among injecting drug users in Vietnam: a review of the research evidence. Curr HIV Res. 2012;10:479-86.

4. Ahmed T, Long TN, Huong PT, Stewart DE. Drug injecting and HIV risk among injecting drug users in Hai Phong, Vietnam: a qualitative analysis. BMC Public Health. 2015;15:32.

5. Quan VM, Go VF, le Nam V, Bergenstrom A, Thuoc NP, Zenilman J, et al. Risks for HIV, HBV, and HCV infections among male injection drug users in northern Vietnam: a case-control study. AIDS Care. 2009;21:7-16.

6. Des Jarlais DC, Friedman SR. Shooting galleries and AIDS: infection probabilities and 'tough' policies. Am J Public Health. 1990;80:142-4.

7. Garfein RS, Doherty MC, Monterroso ER, Thomas DL, Nelson KE, Vlahov D. Prevalence and incidence of hepatitis $C$ virus infection among young adult injection drug users. J Acquir Immune Defic Syndr Hum Retrovirol. 1998; 18(Suppl 1):S11-9.

8. Zhou YH, Yao ZH, Liu FL, Li H, Jiang L, Zhu JW, et al. High prevalence of HIV, HCV, HBV and co-infection and associated risk factors among injecting drug users in Yunnan province, China. PLoS One. 2012;7:e42937.

9. Carlson R. Shooting galleries, dope houses, and injection doctors: examining the social ecology of HIV risk behaviors among drug injectors in Dayton, Ohio. Hum Organ. 2000;59:325-33.

10. Rhodes T, Singer M, Bourgois P, Friedman SR, Strathdee SA. The social structural production of HIV risk among injecting drug users. Soc Sci Med. 2005:61:1026-44.

11. Wojcicki JM. Socioeconomic status as a risk factor for HIV infection in women in East, Central and Southern Africa: a systematic review. J Biosoc Sci. 2005;37:1-36. 
12. Ogunmola OJ, Oladosu YO, Olamoyegun MA. Relationship between socioeconomic status and HIV infection in a rural tertiary health center. HIV AIDS (Auckl). 2014;6:61-7.

13. Tran TM, Nguyen HT, Yatsuya H, Hamajima N, Nishimura A, Ito K. HIV prevalence and factors associated with HIV infection among male injection drug users under 30: a cross-sectional study in Long An, Vietnam. BMC Public Health. 2006;6:248.

14. Malqvist M, Hoa DT, Liem NT, Thorson A, Thomsen S. Ethnic minority health in Vietnam: a review exposing horizontal inequity. Glob Health Action. 2013;6:1-19.

15. Des Jarlais DC, Bramson HA, Wong C, Gostnell K, Cepeda J, Arasteh K, et al. Racial/ethnic disparities in HIV infection among people who inject drugs: an international systematic review and meta-analysis. Addiction. 2012;107:2087-95

16. Ethnic groups in Viet Nam: an analysis of key indicators from the 2009 Viet Nam population and household census. http://vietnam.unfpa.org/ publications/ethnic-groups-viet-nam. Accessed on 27 Jan 2017.

17. Ethnic minorities, drug use and harm in the highlands of northern Vietnam. http://www.unodc.org/pdf/vietnam/vietnam_ethnic_minorities_report.pdf. Accessed on 05 Mar 2017.

18. Results from the HIV/STI integrated biological and behavioral surveillance (IBBS) in Vietnam-Round II -2009. http://www.fhi 360.org/sites/default/files/ media/documents/Integrated\%20Biological\%20and\%20Behavioral\%20 Surveillance\%20Round\%20ll-2012 0.pdf. Accessed on 27 Jan 2017.

19. Hammett TM, Des Jarlais DC, Kling R, Kieu BT, McNicholl JM, Wasinrapee $P$, et al. Controlling HIV epidemics among injection drug users: eight years of cross-border HIV prevention interventions in Vietnam and China. PLoS One. 2012; 7:e43141.

20. Hosmer DW, Lemeshow S. Applied logistic regression. New York: Wiley; 2000.

21. Schneider TR. Getting the biggest bang for your health education buck: message framing and reducing health disparities. Am Behav Sci. 2006;49:812-22.

22. Bui TD, Pham CK, Pham TH, Hoang LT, Nguyen TV, Vu TQ, et al. Cross-sectional study of sexual behaviour and knowledge about HIV among urban, rural, and minority residents in Viet Nam. Bull World Health Organ. 2001;79:15-21.

23. HIV/STI integrated biological and behavioral surveillance (IBBS) in Vietnam-results from round III 2013 and trends across three rounds (2005-2009-2013) of surveys. http:/nihe.org.vn/farm/nihe/2016/07/21/a80ec0a3-41c9-4bd3-a82f-3c04633b8051. pdf. Accessed on 1 Feb 2018

24. Nadol P, O'Connor S, Duong H, Le LV, Thang PH, Tram TH, et al. Findings from integrated behavioral and biologic survey among males who inject drugs (MWID) - Vietnam, 2009-2010: evidence of the need for an integrated response to HIV, hepatitis B virus, and hepatitis C virus. PLoS One. 2015;10:e0118304.

25. Broz D, Wejnert C, Pham HT, DiNenno E, Heffelfinger JD, Cribbin M, et al. HIV infection and risk, prevention, and testing behaviors among injecting drug users-National HIV Behavioral Surveillance System, 20 U.S. cities, 2009. MMWR Surveill Summ. 2014;63:1-51.

26. Final update summary: Human immunodeficiency virus (HIV) infection: Screening U.S. Preventive Services Task Force. September 2016. https:/www. uspreventiveservicestaskforce.org/Page/Document/UpdateSummaryFinal/humanimmunodeficiency-virus-hiv-infection-screening. Accessed on 1 Feb 2018.

27. Paltiel AD, Weinstein MC, Kimmel AD, Seage GR 3rd, Losina E, Zhang $H$, et al. Expanded screening for HIV in the United States-an analysis of cost-effectiveness. N Engl J Med. 2005;352:586-95.

28. Li J, Gilmour S, Zhang H, Koyanagi A, Shibuya K. The epidemiological impact and cost-effectiveness of HIV testing, antiretroviral treatment and harm reduction programs. AIDS. 2012;26:2069-78.

29. Marrazzo JM, del Rio C, Holtgrave DR, Cohen MS, Kalichman SC, Mayer KH, et al. HIV prevention in clinical care settings: 2014 recommendations of the international antiviral society-USA panel. JAMA. 2014;312:390-409.

30. Bergenstrom A, Go V, Nam LV, Thuy BT, Celentano DD, Frangakis C, et al. Return to post-test counselling by out-of-treatment injecting drug users participating in a cross-sectional survey in north Vietnam. AIDS Care. 2007; 19:935-9.

31. Sullivan SG, Wu Z, Detels R. Missed opportunities for HIV testing and counselling in Asia. AIDS. 2010;24(Suppl 3):S49-53.

32. WHO, UNAIDS, UNODC. Technical guide for countries to set targets for universal access to HIV prevention, treatment and care for injecting drug users. Geneva: World Health Organization; 2009.

33. Tran BX, Nguyen LH, Nguyen LP, Nguyen CT, Phan HT, Latkin CA Methadone maintenance treatment promotes referral and uptake of HIV testing and counselling services amongst drug users and their partners. PLoS One. 2016;11:e0152804.
34. Tran BX, Nguyen LT. Impact of methadone maintenance on health utility, health care utilization and expenditure in drug users with HIV/AIDS. Int J Drug Policy. 2013;24:e105-10.

35. Duong HT, Des Jarlais DC, Khuat OHT, Arsteh K, Feelemyer J, Khue PM, et al. Risk behaviors for HIV and HCV infection among people who inject drugs in Hai Phong, Vietnam, 2014. AIDS Behav (2017). https://link.springer.com/ article/10.1007\%2Fs10461-017-1814-6\#citeas

36. Go VF, Frangakis C, le Nam V, Bergenstrom A, Sripaipan T, Zenilman JM, et al. High HIV sexual risk behaviors and sexually transmitted disease prevalence among injection drug users in Northern Vietnam: implications for a generalized HIV epidemic. J Acquir Immune Defic Syndr. 2006;42:108-15.

37. Hammett TM, Des Jarlais D, Johnston P, Kling R, Ngu D, Liu W, et al. HIV prevention for injection drug users in China and Vietnam: policy and research considerations. Glob Public Health. 2007;2:125-39.

38. Philbin M, Pollini RA, Ramos R, Lozada R, Brouwer KC, Ramos ME, et al Shooting gallery attendance among IDUs in Tijuana and Ciudad Juarez, Mexico: correlates, prevention opportunities, and the role of the environment. AIDS Behav. 2008;12:552-60.

39. Lim TW, Davis WW, Quan VM, Frangakis C, Viet T, Minh NL, et al. Association between HIV knowledge and risk behavior in persons who inject drugs in Thai Nguyen, Vietnam. Southeast Asian J Trop Med Public Health. 2014;45: 1425-36.

40. Griffiths P, Gossop M, Powis B, Strang J. Reaching hidden populations of drug users by privileged access interviewers: methodological and practical issues. Addiction. 1993;88:1617-26.

41. Powis B, Strang J, Griffiths P, Taylor C, Williamson S, Fountain J, et al. Selfreported overdose among injecting drug users in London: extent and nature of the problem. Addiction. 1999;94:471-8.

42. Volz E, Heckathorn DD. Probability based estimation theory for respondent driven sampling. J Off Stat. 2008;24:79.

\section{Submit your next manuscript to BioMed Central and we will help you at every step:}

- We accept pre-submission inquiries

- Our selector tool helps you to find the most relevant journal

- We provide round the clock customer support

- Convenient online submission

- Thorough peer review

- Inclusion in PubMed and all major indexing services

- Maximum visibility for your research

Submit your manuscript at www.biomedcentral.com/submit
) Biomed Central 